\title{
EFEITO DO TRATAMENTO COM FONTES DE ZINCO E BORO NA GERMINAÇÃO E VIGOR DE SEMENTES DE MILHO'
}

\author{
N.D. RIBEIRO; O.S. dos SANTOS; N.L. de MENEZES \\ Departamento de Fitotecnia-UFSM, CEP: $97119-900$ - Santa Maria,RS
}

\begin{abstract}
RESUMO: Foi conduzido um experimento no Departamento de Fitotecnia da Universidade Federal de Santa Maria, RS, no periodo de março a novembro de 1992, com o objetivo de verificar o efeito da aplicação de fontes de zinco e boro em sementes de milho tratadas ou não com defensivos agricolas. Adotou-se o esquema fatorial $3 \times 2 \times 6$, em delineamento inteiramente casualizado, com quatro repetições. Os tratamentos constaram de avaliaçōes em três épocas (logo apos o tratamento, quatro e oito meses depois), utilização de sementes de milho com e sem tratamento fitossanitário, combinados com seis fontes de zinco e boro (testemunha, Zn-Biocrop, B-Biocrop, B-Orgânico, Zn-Biocrop + B-Biocrop e Zn-Biocrop + B-Orgânico), nas doses únicas de $2,50 \mathrm{~g} \mathrm{Zn} \mathrm{e} \mathrm{de} 0,15 \mathrm{~g}$ B/kg de sementes. Os resultados obtidos mostram que a aplicação da fonte Zn-Biocrop não prejudica a germinaçâo e o vigor, pelo período de oito meses de armazenamento. 0 tratamento de sementes com boro (B-Biocrop e B-Orgânico) diminui a germinação e o vigor.
\end{abstract}

Descritores: milho, zinco, boro, germinação, vigor

\section{EFFECTS OF MAIZE SEED TREATED WITH ZINC AND BORON SOURCES ON GERMINATION AND VIGOUR}

\begin{abstract}
The experiment was carried during the period of march 1992 to november 1992, to study the effects of maize seed treatment with zinc, boron and pesticides, on the germination and vigour during storage. The experimental design was a complete randomized $3 \times 2 \times 6$ fatorial with four replications. The treatments were three storage periods (zero, four and eight month), pesticides treatments with or without, and six sources of zinc and boron (control, Zn-Biocrop, B-Biocrop, Organic-B, Zn-Biocrop + B-Biocrop and Zn-Biocrop + Organic-B), in the dose $2.50 \mathrm{~g}$ of the $\mathrm{Zn}$ and $0.15 \mathrm{~g}$ of the $\mathrm{B} / \mathrm{kg}$ of seeds. The results show that $\mathrm{Zn}$-Biocrop maintain high germination and vigour for eight month of storage. The boron treatment (B-Biocrop and Organic-B) showed a low germination and vigour.
\end{abstract}

Key Wonds: maize, zinc, boron, germination, vigour

\section{INTRODUÇÃo}

O zinco e o boro são os micronutrientes que, com mais freqüência, se mostram deficientes em solos brasileiros. Estima-se que cerca de 170 milhões de ha de solos, sob vegetação de Cerrado do Brasil Central, sejam deficientes em zinco e, cerca de 108 milhões de ha, deficientes em boro (LOPES, 1984). A carência destes micronutrientes reflete no crescimento e na produção, pois desempenham importantes funções na planta.

Uma das formas de suprir zinco e boro às plantas consiste na sua aplicação nas sementes. No entanto, o tratamento de sementes realizado pelo agricultor pode causar incorreções, pois há pequena amplitude de variação entre a dose recomendada e o aparecimento de deficiência ou toxicidade. Para tanto, busca-se uma alternativa mais precisa para o tratamento de sementes, na indústria, aproveitando a etapa de beneficiamento, onde são adicionados os defensivos agrícolas, para acrescentar micronutrientes. Resta conhecer a qualidade fisiológica das sementes tratadas com zinco e boro, durante o período em que são normalmente armazenadas, e se ocorre incompatibilidade ou não com os defensivos agrícolas rotineiramente utilizados pelas empresas produtoras de sementes de milho.

\footnotetext{
${ }^{1}$ Trabalho apresentado no VIII Congresso Brasileiro de Sementes, Fóz do Iguaçu, PR, em 23.08.93.
}

Sci. agric., Piracicaba, 51(3):481-485, set./dez. 1994 
Em vista disso, o presente trabalho objetivou verificar o efeito da aplicação de fontes de zinco e boro em sementes de milho tratadas ou não com defensivos agrícolas, durante oito meses de armazenamento.

\section{MATERIAL E METOBOS}

O experimento foi conduzido no Departamento de Fitotecnia da Universidade Federal de Santa Maria, RS, no período de março a novembro de 1992. O lote de sementes de milho (hibrido Pionner 3069, peneira C-2) apresentava, no início do experimento, peso de 1000 sementes de $376,3 \mathrm{~g}, 10,3 \%$ de umidade e $14,0 \%$ de danos mecânicos, sendo este último avaliado pelo teste verde malaquita (MARCOS FILHO et al., 1987).

Adotou-se o esquema fatorial $3 \times 2 \times 6$, em delineamento inteiramente casualizado, com quatro repetições. Os tratamentos constaram de avaliações em três épocas (logo após o tratamento das sementes, quatro e oito meses depois), utilização de sementes com e sem tratamento fitossanitário (mistura de Captan, Deltametrina, Actelic e Ceanil). $O$ último fator foi composto de seis fontes de zinco e boro: testemunha (sem aplicação de zinco e boro), Zn-Biocrop (produto pó micronizado, composto de fontes orgânicas e inorgânicas, com $50,0 \% \mathrm{Zn}$ ), B-Biocrop (produto pó micronizado, composto de fontes orgânicas e inorgânicas, com 5,0\% B), B-Orgânico (fonte orgânica viscosa, com $10,4 \%$ B), Zn-Biocrop + B-Biocrop e Zn-Biocrop + B-Orgânico. As fontes de zinco e boro foram utilizadas nas doses únicas de $2,50 \mathrm{~g} \mathrm{Zn}$ e de $0,15 \mathrm{~g} \mathrm{~B} / \mathrm{kg}$ de sementes, respectivamente. As fontes na forma de pó foram aplicadas sobre as sementes umedecidas $(15 \mathrm{ml} \mathrm{de}$ água desionizada/kg de sementes) e as fontes orgânicas foram diluídas em água desionizada e aplicadas sobre as sementes que, a seguir, foram homogeneizadas e secadas à sombra.

Realizou-se o teste padrão de germinação, em substrato rolo de papel (BRASIL, 1980), excetuando-se o número de sementes que foi de 200 , em quatro repetições de 50 sementes por tratamento. A avaliação da germinação foi realizada em apenas uma contagem, aos seis dias após a semeadura. Nesse momento, as plântulas normais foram separadas, acondicionadas em sacos de papel e levadas à estufa $\left(6^{\circ} \mathrm{C}\right)$ até peso constante, quando determinou-se a massa seca das plântulas excisadas dos resíduos de endosperma $\mathrm{e}$ pericarpo.

Sci. agric., Piracicaba, 51(3):481-485, set./dez. 1994
Para avaliar o vigor, utilizou-se a massa seca das plântulas normais, do teste de germinação, e o teste de envelhecimento precoce. Este último seguiu a metodologia sugerida por MARCOS FILHO et al. (1987) onde, após o envelhecimento sob a condição de $4^{\circ} \mathrm{C}$ por 96 horas, as sementes foram transferidas para substrato rolo de papel e realizado o mesmo procedimento do teste padrão de germinação.

Os resultados obtidos foram submetidos à análise da variância. Como a interação foi significativa, optou-se por fazer o desdobramento de micronutrientes dentro de defensivos agrícolas, sendo as médias entre os tratamentos comparadas pelo teste de Duncan a 5\% de probabilidade.

\section{RESULTADOS E DISCUSSÃO}

A germinação foi influenciada pelas fontes de zinco e boro, em presença ou não de defensivos agrícolas, bem como pela interação destes nas épocas estudadas (Figura 1).
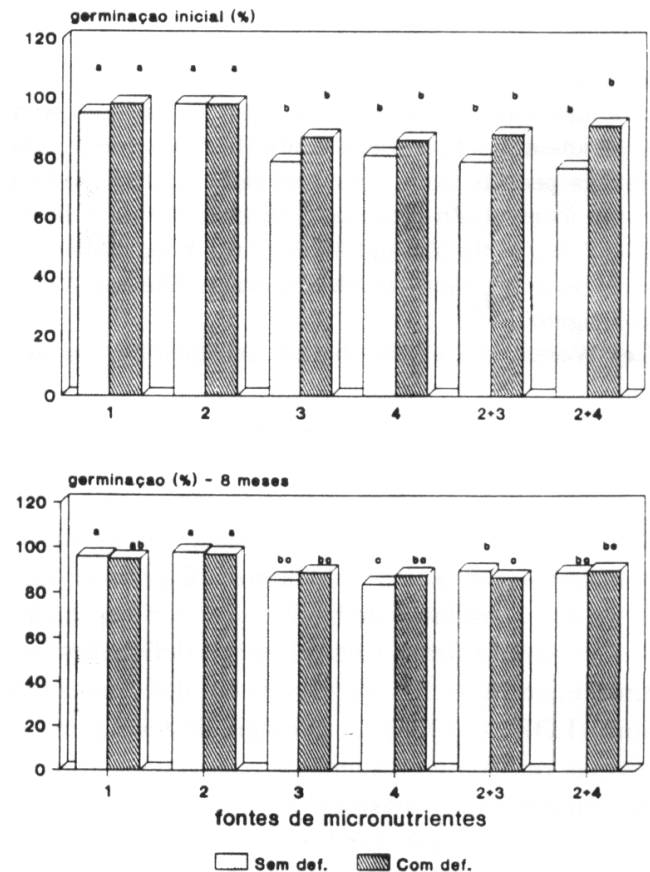

Figura 1. Germinação de sementes de milho tratadas com defensivos agrícolas e fontes de zinco e boro ( $1=$ testemunha; 2=Zn-Biocrop; 3=B-Biocrop; 4=BOrgânico). Santa Maria,RS, 1992. 
Quando foi avaliada a germinação, logo após o tratamento das sementes, observou-se que as fontes de zinco e boro apresentaram comportamento similar, tanto na presença quanto na ausência de defensivos agrícolas (Figura 1).

Na presença de defensivos agrícolas, apenas o Zn-Biocrop manteve alta germinação (98\%), não diferindo significativamente da testemunha. Resultado semelhante foi obtido por RIBEIRO (1993), com a aplicação de $2,50 \mathrm{~g} \mathrm{Zn} / \mathrm{kg}$ de sementes da fonte $\mathrm{Zn}$-Biocrop, onde o aumento do teor de zinco em cerca de 18 vezes não foi tóxico para as sementes de milho, possibilitando maior fornecimento de zinco para o início do crescimento das plântulas, especialmente em condições de deficiência de zinco no substrato ou em temperatura do ar e intensidade luminosa baixas (EDWARDS \& KAMPRATH, 1974; EDWARDS \& KAMPRATH, 1975). Deve ser salientado que o objetivo do tratamento de sementes é o de torná-las ricas no nutriente que, posteriormente, será transferido para as plantas (MELO, 1990; DALMOLIN, 1992). As demais fontes de zinco e boro reduziram significativamente a germinação; no entanto não restringiram a utilização das sementes de milho, porque os valores obtidos permaneceram acima do mínimo requerido pelas Normas de Produção de Semente Fiscalizada (BRASIL, 1992).

Na ausência de defensivos agrícolas, apenas a aplicação de $\mathrm{Zn}$-Biocrop não diferiu da germinação da testemunha (98\%) (Figura 1). As demais fontes de zinco e boro provocaram redução da germinação, inviabilizando a utilização das sementes de milho.

No entanto, era esperado que a aplicação de zinco propiciasse efeitos positivos sobre a germinação, como foi observado em trigo por CHENG (1955). Provavelmente, o incremento de $89 \%$ na germinação de sementes de trigo, constatado por este autor, tenha sido decorrente de melhorias na sanidade e no vigor em resposta ao tratamento de sementes com zinco. No presente trabalho, não foram observados efeitos positivos da aplicação de zinco na germinação, possivelmente, em virtude do elevado valor inicial (98\%).

0 armazenamento por quatro meses após o tratamento das sementes com fontes de zinco e boro não alterou, consideravelmente, as características iniciais do lote, mantendo os dados de germinação, massa seca e vigor semelhantes aos valores obtidos logo aposs o tratamento das sementes; por esse motivo não estão apresentados os dados desta época de avaliação.

0 armazenamento por oito meses após o tratamento das sementes manteve a germinação da testemunha, tanto na presença de defensivos agrícolas (95\%), como na sua ausência (96\%) (Figura 1). Na presença de defensivos agrícolas, apenas o $\mathrm{Zn}$-Biocrop manteve a germinação em $97 \%$, não diferindo significativamente do valor obtido pela testemunha. Resultado semelhante foi verificado, com essa mesma fonte, em milho por RIBEIRO \& SANTOS (1991) e RIBEIRO (1993), com as doses de 3,00 e $2,50 \mathrm{~g} \mathrm{Zn} / \mathrm{kg}$ de sementes, respectivamente, possibilitando que as sementes tratadas fossem armazenadas sem prejuízos à germinação. As demais fontes provocaram diminuição deste parâmetro. No entanto, em todos os tratamentos com fontes de zinco e boro, os valores de germinação permaneceram acima do mínimo requerido pelas Normas de Produção de Semente Fiscalizada (BRASIL, 1992) para a comercialização de sementes de milho. $\mathrm{Na}$ ausência de defensivos agrícolas, foi obtida resposta semelhante.

Quando foi avaliado o vigor, através da produção de massa seca, logo após o tratamento de sementes, observou-se resposta diferenciada para as fontes de zinco e boro (Figura 2). A massa seca inicial do lote foi similar para a testemunha com e sem defensivos agrícolas (195mg e $197 \mathrm{mg} /$ plântula, respectivamente). $\mathrm{Na}$ presença de defensivos agrícolas, observou-se que o $\mathrm{Zn}$-Biocrop manteve a massa seca em valor significativamente semelhante ao obtido pela testemunha. No entanto, as demais fontes de zinco e boro propiciaram incrementos significativos na produção de massa seca, com valor máximo para a combinação Zn-Biocrop + B-Orgânico (240mg/plântula), o que representa aumento médio de $23 \%$ na massa seca das plântulas. Esses resultados concordam com os obtidos por CHENG (1955), que observou incremento de $11,95 \%$ na produção de massa seca da parte aérea e $34,52 \%$ na massa seca das raízes de plântulas de trigo oriundas de sementes imersas, por 24 horas, em solução com $0,25 \mathrm{mg} / 1 \mathrm{de}$ $\mathrm{ZnSO}_{4} \cdot 4 \mathrm{H}_{2} \mathrm{O}$. Na ausência de defensivos agrícolas foi obtido comportamento similar.

0 armazenamento por oito meses, após o tratamento das sementes, propiciou redução da massa seca da testemunha como conseqüência natural do processo de deterioração das sementes, resultando em menor desenvolvimento das plântulas (Figura 2). Na presença de defensivos agrícolas, a massa seca da testemunha diminuiu de 195 para 
$91 \mathrm{mg} /$ plântula, o que representa redução média de $47 \%$. Observou-se que, com a fonte $\mathrm{Zn}$-Biocrop, essa diminuição foi menos intensa, de 199 para $118 \mathrm{mg} /$ plântula, resultando em aparente aumento da massa seca quando as sementes foram armazenadas (Figura 2).
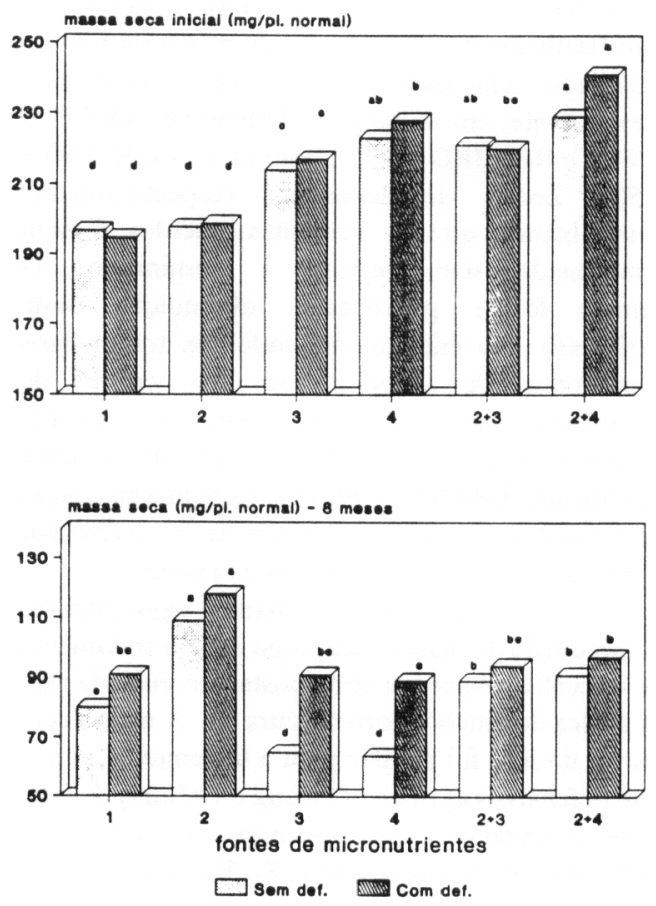

Figura 2. Massa seca de plântulas normais obtida pelo tratamento de sementes de milho com defensivos agrícolas e fontes de zinco e boro $(1=$ testemunha; $2=\mathrm{Zn}$ Biocrop; 3 =B-Biocrop; 4 = B-Orgânico). Santa Maria, UFSM, RS, 1992.

As demais fontes de zinco e boro não diferiram significativamente da testemunha, indicando que as sementes podem ser armazenadas por oito meses após o tratamento sem limitar a produção de massa seca das plântulas. Resultado semelhante foi encontrado em milho com a aplicação de $\mathrm{Zn}$-Biocrop $(2,50 \mathrm{~g} \mathrm{Zn} / \mathrm{kg}$ de sementes) e B-Biocrop $(0,15 \mathrm{~g} \quad \mathrm{~B} / \mathrm{kg}$ de sementes $)$, possibilitando $o$ armazenamento das sementes tratadas por oito meses, sem prejuízos à produção de massa seca (RIBEIRO, 1993). Na ausência de defensivos agrícolas, as fontes de zinco e boro apresentaram comportamento semelhante ao obtido na presença de defensivos agrícolas.
Quando foi avaliado o vigor, através do teste de envelhecimento precoce, logo após o tratamento das sementes, observou-se comportamento diferenciado para as fontes de zinco e boro (Figura 3). Na presença de defensivos agrícolas, a aplicação de Zn-Biocrop manteve o vigor inicial significativamente semelhante ao valor obtido pela testemunha (96\%). Resultado semelhante foi obtido em milho com a aplicação de $2,50 \mathrm{~g} \mathrm{Zn} / \mathrm{kg}$ de sementes, fonte $\mathrm{Zn}$-Biocrop, a qual manteve o vigor da testemunha (90\%) (RIBEIRO, 1993). As demais fontes de zinco e boro reduziram significativamente este parâmetro. $\mathrm{Na}$ ausência de defensivos agrícolas, o Zn-Biocrop e o Zn-Biocrop + B-Biocrop mantiveram o vigor significativamen-te semelhante ao da testemunha $(74 \%) \mathrm{e}$, as demais fontes, provocaram redução neste parâmetro.
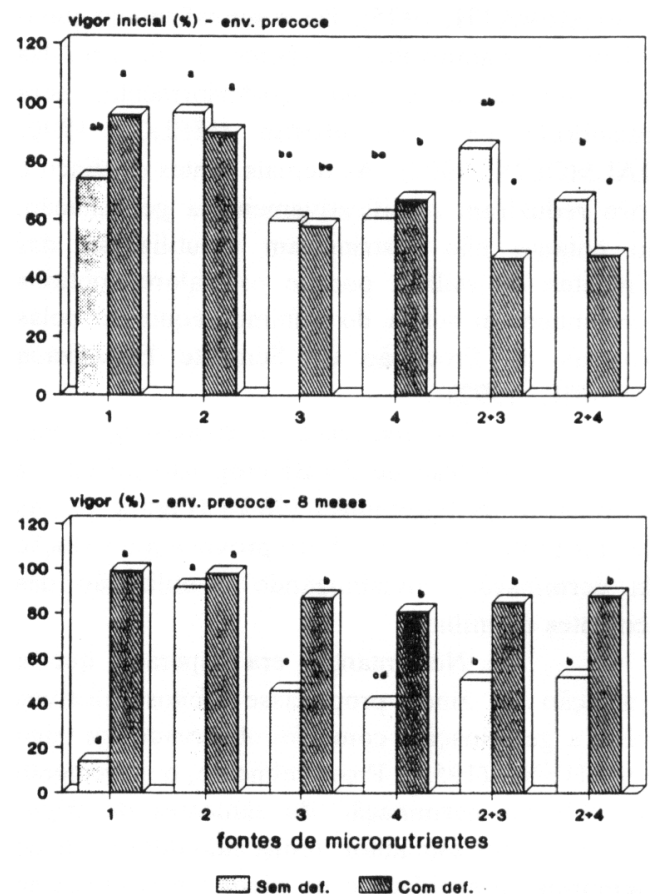

Figura 3. Vigor de sementes de milho tratadas com defensivos agrícolas e fontes de zinco e boro ( $1=$ testemunha; $2=\mathrm{Zn}$-Biocrop; 3=B-Biocrop; 4=B-Orgânico). Santa Maria, UFSM, RS, 1992.

O armazenamento por oito meses após o tratamento das sementes, proporcionou comportamento diferenciado na presença ou não de defensivos agrícolas (Figura 3 ). $\mathrm{Na}$ presença de 
defensivos agrícolas, apenas o $\mathrm{Zn}$-Biocrop manteve vigor $\mathbf{9 8 \%}$ ) significativamente semelhante ao valor obtido pela testemunha. As demais fontes de zinco e boro provocaram diminuição deste parâmetro. $\mathrm{Na}$ ausência de defensivos agrícolas, o vigor da testemunha foi reduzido de 74 para 14, provavelmente em virtude da presença de patógenos (observados visualmente) na semente, que provocaram danos a partir da primeira avaliação. No entanto, a aplicação de fontes de zinco e boro fez com que o vigor não fosse tão afetado, devido a ação de fungicida que estas fontes apresentam. $\mathrm{O} \mathrm{Zn}$-Biocrop, provavelmente por ter melhorado a sanidade, elevou o vigor a $92 \%$, valor equivalente ao obtido com a aplicação de defensivos agrícolas. As demais fontes de zinco e boro propiciaram incrementos no vigor em relação à testemunha.

\section{CONCLUSÕES}

1. O tratamento com $\mathrm{Zn}$-Biocrop não prejudica a germinação e o vigor pelo período de oito meses de armazenamento.

2. O tratamento de sementes com boro (B-Biocrop e B-Orgânico) diminui a germinação e o vigor.

\section{REFERÊNCIAS BIBLIOGRÁFICAS}

BRASIL. Ministério da Agricultura. Divisão de Sementes e Mudas. Regras para análise de sementes. Brasília, DNPV-DISEM, 1980. 188p.

BRASIL. Ministério da Agricultura e Reforma Agrária. Normas para a produção de semente fiscalizada CESM/RS. Porto Alegre, DFRA/RS. 1992. 73p.

CHENG, T. The effect of seed treatment with microelements upon germination and early growth of wheat. Scientia Sinica, Peking, v.4, p.129-135, 1955.
DALMOLIN, R.S.D. Fontes de zinco aplicadas nas sementes de milho cultivado em solução nutritiva com diferentes doses de zinco. Santa Maria, 1992. 84 p. Dissertação (Mestrado) - Universidade Federal de Santa Maria.

EDWARDS, J.H.; KAMPRATH, E.J. Zinc accumulation by corn seedlings as influenced by phosphorus, temperature, and light intensity. Agronomy Journal, Madison, v.66, n.4, p.479-482, 1974.

EDWARDS, J.H.; KAMPRATH, E.J. Zinc accumulation and growth of corn seedlings as affected by endosperm removal. Agronomy Journal, Madison, v.67, n.6, p.809-812, 1975 .

LOPES, A.S. Solos sob cerrado: características, propriedades e manejo. Piracicaba: POTAFós, 1984. $162 p$.

MARCOS FILHO, J.; CICERO, S.M.; SILVA, W.R. Avaliação da qualidade das sementes. Piracicaba: FEALQ, 1987, 230p.

MELO, E.F.R.Q. Respostas de cultivares de feijão (Phaseolus vulgaris L.) a níveis de zinco nas formas inorgânicas e orgânicas, em casa de vegetação e no campo. Curitiba, 1990.125 p. (Dissertação) Mestrado - Universidade Federal do Paraná.

RIBEIRO, N.D. Germinação e vigor de sementes de milho tratadas com fontes de zinco e boro. Santa Maria, 1993. 83 p. Dissertação (Mestrado) Universidade Federal de Santa Maria.

RIBEIRO, N.D.; SANTOS, O.S. Germinação de sementes de milho tratadas com fontes de zinco e boro. Ciência Rural, Santa Maria, v.21, n.3, p.437-440, 1991.

Recebido para publicação em 06.01.94

Aceito para publicação em 20.09.94 